\title{
CARACTERIZAÇ̃̃o ENZIMÁTICA DE ISOFORMAS DE CISTEÍNO PROTEASE DE Anticarsia gemmatalis (HÜBNER, 1818)
}

\author{
Enzymatic characterization of cysteine protease \\ isoforms of Anticarsia gemmatalis (Hübner, 1818)
}

\author{
Eduardo Gomes de Mendonça ${ }^{1}$, Liliane Evangelista Visôtto ${ }^{1}$, Natália Cristina Santos Costa ${ }^{2}$, \\ Fabrício Rainha Ribeiro ${ }^{3}$, Joel Antônio de Oliveira ${ }^{4}$, Maria Goreti de Almeida Oliveira ${ }^{5}$
}

\begin{abstract}
RESUMO
Isoformas de cisteíno protease obtidas do intestino médio de lagartas de $5^{\circ}$ instar de Anticarsia gemmatalis (Hübner, 1818) foram caracterizadas. A isoforma solúvel foi chamada de Fração Solúvel enquanto a isoforma ligada à membrana celular, de Fração Insolúvel. As maiores atividades foram observadas em $\mathrm{pH}$ 3,6 a $45^{\circ} \mathrm{C}$ para a Fração Solúvel e pH 4,6 a $50^{\circ} \mathrm{C}$ para a Fração Insolúvel. Ao analisar o efeito de modificadores químicos, a Fração Solúvel mostrou-se insensível à aprotinina e E-64, porém teve sua atividade aumentada pela adição de EDTA e levemente inibida pela adição de íons $\mathrm{Ca}^{2+}$, mostrando se tratar de enzimas independentes de íons metálicos para sua atividade. A Fração Insolúvel também se mostrou insensível à aprotinina, porém teve sua atividade parcialmente inibida por E-64. A adição de EDTA levou a uma redução nos valores de atividade, demonstrando a necessidade de íons metálicos para a atividade dessas enzimas, porém não se trata de enzimas cálcio-dependentes, uma vez que sua atividade foi reduzida com a adição desse íon. Os valores de $\mathrm{K}_{\mathrm{M} \text { p }} \mathrm{e} \mathrm{V}_{\text {íx }}$ foram, respectivamente, $0,6398 \mathrm{mM}$ e 42,556 $\mathrm{nM} \mathrm{s}^{-1}$ para Fração Solúvel e $0,0413 \mathrm{mM}$ e $10,854 \mathrm{nM} \mathrm{s}^{-1}$ para Fração Insolúvel. Esses resultados fornecem evidências da presença de cisteíno protease solúvel e ligada à membrana celular do intestino de lagartas de A. gemmatalis. O conhecimento e a caracterização das principais classes de proteases presentes no trato digestivo da lagarta da soja, bem como a interação dessas enzimas com inibidores de protease têm uma importante consequência aos programas de melhoramento de soja.
\end{abstract}

Termos para indexação: Proteases digestivas, Lepidoptera, controle de pragas, inibição de proteases.

\section{ABSTRACT}

Cysteine protease isoforms obtained from the midgut of $5^{\text {th }}$ instar Anticarsia gemmatalis (Hübner, 1818) larvae were characterized. The soluble enzyme isoform was called Soluble Fraction and cell membrane-bound enzyme isoform, the Insoluble Fraction. The highest activities were observed at $\mathrm{pH} 3.6$ and $45^{\circ} \mathrm{C}$ for the Soluble Fraction and $\mathrm{pH} 4.6$ and $50^{\circ} \mathrm{C}$ for the Insoluble Fraction. Analyzing the effect of chemical modifiers, the Soluble Fraction was shown to be insensitive to aprotinin and E-64, although its activity was increased by the addition of EDTA and slightly inhibited by the addition of $\mathrm{Ca}^{2+}$, showing to be enzymes independent of metal ions to its activity. The Insoluble Fraction was also insensitive to aprotinin, but its activity was partially inhibited by E-64. The addition of EDTA reduced the activity values, demonstrating the need for metal ions for the activity of these enzymes, but they are not calcium-dependent enzymes, since their activity was reduced with the addition of this ion. The values of $\mathrm{K}_{\mathrm{M}}$ and $\mathrm{V}_{\mathrm{m}}$ were, respectively, $0.6398 \mathrm{mM}$ and $42.556 \mathrm{nM} \mathrm{s}^{-1}$ for Soluble Fraction and $0.0413 \mathrm{mM}$ and $10.854 \mathrm{nM} \mathrm{s}^{-1}$ for Insoluble Fraction. These results provide evidence for the presence of soluble and cell membrane-bound cysteine proteases in the gut of A. gemmatalis larvae. The knowledge and characterization of the major classes of proteases produced by the digestive tract of the soybean caterpillar, as well as the interaction of these enzymes with protease inhibitors, have a major implication for soybeans breeding programs.

Index terms: Digestive proteases, Lepidoptera, pest control, protease inhibition.

(Recebido em 16 de abril de 2010 e aprovado em 11 de novembro de 2010)

\section{INTRODUÇÃO}

Um dos métodos potenciais no controle de doenças e pragas é a indução de resistência, que se caracteriza pela ativação dos mecanismos de defesa inerentes da planta (Meneghetti et al., 2010). Os inibidores de proteases (IPs) são naturalmente produzidos pelas plantas e estão intimamente relacionados ao mecanismo de defesa delas à herbivoria (Pilon et al., 2006). Os IPs com atividade entomotóxica têm sido amplamente estudados através de transgênia ou por análises de inibição de proteases

'Universidade Federal de Viçosa/UFV - Departamento de Bioquímica e Biologia Molecular - Viçosa, MG

2Universidade Federal de Viçosa/UFV - Departamento de Biologia Geral - Viçosa, MG

${ }^{3}$ Universidade Federal de Viçosa/UFV - Departamento de Biologia Animal - Viçosa, MG

${ }^{4}$ Universidade Federal de Viçosa/UFV - Departamento de Química - Viçosa, MG

5Universidade Federal de Viçosa/UFV - Departamento de Bioquímica e Biologia Molecular - Campus Universitário - s/n - Centro - $36571-000$ - Viçosa, MG -36571-000 - malmeida@ufv.br

Ciênc. agrotec., Lavras, v. 35, n. 3, p. 446-454, maio/jun., 2011 
digestivas in vitro (Pilon et al., 2006). Eles funcionam como substratos específicos das proteases digestivas dos insetos, formando um complexo estável no qual a proteólise é limitada e extremamente lenta (Tiffin \& Gaut, 2001). A ingestão crônica desses inibidores pelo inseto acarreta uma deficiência em aminoácidos essenciais, que influencia no seu crescimento e desenvolvimento. Considerando o efeito antinutricional dos inibidores, a avaliação da eficiência destes para a produção de plantas resistentes a pragas tem despertado grande interesse. Acredita-se que o sucesso da estratégia de controle de pragas baseada no uso de inibidores de proteases depende de uma análise caso a caso, envolvendo necessariamente o conhecimento mais detalhado das enzimas digestivas presentes no intestino do inseto alvo.

Anticarsia gemmatalis (Hübner, 1818) (Lepidoptera: Noctuidae), também conhecida como lagarta da soja, é considerada praga da sojicultura, sendo responsável por grandes prejuízos a essa cultura. Embora inseticidas químicos sintéticos tenham se firmado como um método eficiente no controle desse inseto-praga, o fato de promoverem danos à natureza e ao homem tem motivado uma incessante busca por novas formas de proteção de cultivos agrícolas. Proteases digestivas, em especial as serino proteases (Oliveira et al., 2005; Xavier et al., 2005) e proteases produzidas pela microbiota (Visôtto et al., 2009), já foram bem caracterizadas nesse inseto. Porém, há outra classe importante de proteases produzidas por essa lepidóptera, as cisteíno proteases. Algumas isoenzimas de cisteino proteases foram reconhecidas e seus genes sequenciados em Tenebrio molitor (Linnaeus, 1758) (Cristofoletti et al., 2005).

Dessa forma, foi realizada, no presente trabalho, a caracterização dos parâmetros bioquímicos e cinéticos de isoformas de cisteíno protease solúvel e ligada à membrana celular encontrada no trato intestinal de $A$. gemmatalis, e também foi avaliado o comportamento dessa enzima diante de vários inibidores sintéticos. Esses resultados são de grande importância ao uso de inibidores como método de controle dessa praga.

\section{MATERIAL E MÉTODOS}

Anticarsia gemmatalis foi criada em dieta artificial descrita por Hoffman-Campo et al. (1985) e mantidas sob condições controladas de $25 \pm 5^{\circ} \mathrm{C}, 70 \pm 10 \%$ U.R. e fotoperíodo de 14:10 (L:D). Lagartas de quinto ínstar foram usadas nos experimentos. Todos os reagentes foram obtidos da Sigma-Aldrich Brasil Ltda (São Paulo, SP, Brasil).

Os intestinos médios foram extraídos após dissecação de larvas de $5^{\circ}$ ínstar e colocados em solução
$\mathrm{HCl} 10^{-3} \mathrm{M}$ na proporção de 5 intestinos para cada $\mathrm{mL}$ de solução e mantidos a $4^{\circ} \mathrm{C}$. O extrato enzimático foi obtido através do rompimento celular resultante de nove ciclos de congelamento em nitrogênio líquido e descongelamento em banho-maria a $37^{\circ} \mathrm{C}$. Após os ciclos, o extrato foi centrifugado a $23.500 \mathrm{~g}$ por $10 \mathrm{~min}$ a $4^{\circ} \mathrm{C}$ (Oliveira et al., 2005). O sobrenadante contendo o material solúvel foi denominado de Fração Solúvel, enquanto o precipitado foi utilizado para a extração de cisteíno proteases ligadas à membrana celular, o qual foi solubilizado em $10 \mathrm{~mL}$ de solução $\mathrm{HCl} 10^{-3} \mathrm{M}$ contendo $0,5 \%$ do detergente Brij 35 e centrifugado a $23.500 \mathrm{~g}$ por $10 \mathrm{~min}$ a $4^{\circ} \mathrm{C}$. O uso de detergente garante a extração de enzimas ligadas à membrana celular devido ao caráter lipolítico dessas. $\mathrm{O}$ sobrenadante obtido dessa extração foi chamado de Fração Insolúvel. Tanto a Fração Solúvel quanto a Insolúvel foram mantidas a $-20^{\circ} \mathrm{C}$ para análises posteriores.

A atividade amidásica de cisteíno-proteases foi determinada pelo método modificado descrito por Erlanger et al. (1961), utilizando-se o substrato cromogênico Nbenzoil-L-arginil-p-nitroanilina (L-BapNA) 1,2 mM, tampão Tris- $\mathrm{HCl} 0,1 \mathrm{M} \mathrm{pH} \mathrm{8,2} \mathrm{contendo} 10 \mathrm{mM}$ do agente redutor ß-mercaptoetanol, inibidor de serino e aspartil protease Benzamidina $12 \mathrm{mM}$ e Pepstatina A $1 \mu \mathrm{M}$, respectivamente. $\mathrm{O}$ uso dos inibidores impede a atividade de outras proteases no ensaio, eliminando, dessa forma, uma possível interferência.

$\mathrm{O}$ efeito do $\mathrm{pH}$ na atividade das enzimas foi determinado a $25^{\circ} \mathrm{C}$ utilizando a faixa de $\mathrm{pH}$ de 2,0 a 10,0. Para avaliar o efeito da temperatura na atividade de cisteíno proteases, foi utilizado banho-maria e Espectrofotômetro Scanning UV-VIS modelo Nicolet Evolution 100 com sistema de temperatura controlada e as temperaturas variaram de 10 a $60^{\circ} \mathrm{C}$.

A determinação dos parâmetros cinéticos $\mathrm{K}_{\mathrm{M} \text { app }} \mathrm{e}$ $\mathrm{V}_{\text {max app }}$ foi realizada no $\mathrm{pH}$ e na temperatura de melhor atividade de cada fração. A faixa de concentração utilizada do substrato L-BApNA foi de 0,4 a 4,0 mM para a Fração Solúvel e de 0,05 a 1,0 mM para a Fração Insolúvel. Os parâmetros cinéticos, no estado estacionário, foram obtidos por meio de regressão não-linear, empregando-se o programa de computação Sigma Plot 10.0.

No estudo de modificadores químicos na atividade de cisteíno proteases de A. gemmatalis foi utilizado L-BApNA como substrato, na presença de: Pepstatina A $(0-10 \mu \mathrm{M})$, EDTA $(0-100 \mathrm{mM})$; Aprotinina $(0-4 \mu \mathrm{M})$ e E-64 $(0-100 \mu \mathrm{M})$. O efeito dos íons cálcio na atividade enzimática das duas Frações também foi determinado. Ao tampão, foi adicionado $\mathrm{CaCl}_{2}$ que teve suas concentrações variando de 5 a $30 \mathrm{mM}$. 


\section{RESULTADOS E DISCUSSÃO}

Várias classes de proteases já foram caracterizadas em insetos. Rossi et al. (2009) estudaram várias classes enzimáticas digestivas de Leucoptera coffeella (GuérinMèneville \& Perrottet, 1842), um lepidóptero popularmente conhecida como bicho-mineiro do cafeeiro, e constataram que o processo digestivo desse inseto é similar ao de outros lepidópteros encontrados na literatura. Os parâmetros bioquímico-cinéticos de serino proteases do extrato solúvel e ligadas à membrana celular do intestino médio da lagarta da soja são bem conhecidos (Oliveira et al., 2005; Xavier et al., 2005). Porém, o segundo grupo de proteases funcionais que exercem papel significativo na digestão de proteínas na lagarta da soja são as cisteíno proteases (Terra \& Ferreira, 1994). A atividade proteásica no intestino de $A$. gemmatalis é devida, em sua maior parte, à atividade de serino proteases. Quando essas são inibidas in vitro, torna-se aparente a atividade de cisteíno protease, desde que obedecidas as exigências reacionais dessa classe de proteases, ou seja, adição de um agente redutor para garantir que a cisteína do centro ativo esteja cataliticamente disponível e, caso a enzima não esteja purificada, a adição de um inibidor de serino protease. Pereira et al. (2005) utilizaram azocaseína para medir atividade proteásica de A. gemmatalis e afirmaram que esse inseto não possui atividade de cisteíno protease em seu intestino, quando utilizaram 2-marcaptoetanol e L-cisteína no meio de reação, os quais não aumentaram a hidrólise de azocaseína, porém não utilizaram um inibidor de serino protease. Quando utilizaram o inibidor de cisteíno protease ácido iodoacético, a atividade proteásica total caiu $4 \%$. Desse modo não há relatos na literatura de estudos envolvendo Anticarsia gemmatalis e caracterização de cisteíno proteases. Inicia-se, com o presente trabalho, uma série de estudos de cisteíno proteases da lagarta da soja e sua relevância na interação inseto-soja. A atividade de cisteíno proteases presentes nos extratos enzimáticos das Frações Solúvel e Insolúvel foi determinada sobre o substrato L-BApNA. A atividade enzimática foi medida em diferentes valores de $\mathrm{pH}$; os perfis de atividade obtidos foram distintos para ambas as frações (Figuras 1A e 1B) e a existência de diferentes picos sugere uqe há diferentes isoformas de cisteíno nesses extratos. A maior atividade foi obtida em pH 3,6 e 8,0 para a Fração Solúvel e pH 4,6 e 8,0 para a Fração Insolúvel. Dessa forma, os resultados mostram que a atividade enzimática foi maior, em ambas as frações, nas faixas de $\mathrm{pH}$ de 3,5- 5,0 e 7,5 - 8,0. Estes dados estão de acordo com aqueles encontrados por Zhao et al. (1998) em estudos de uma cisteíno protease purificada de Helicoverpa armigera (Hübner, 1805), nos quais o $\mathrm{pH}$ em que houve maior atividade foi na faixa de 3,0 - 4,0. Pyati et al. (2009), trabalhando com cisteíno proteases (catepsina L-like) recombinantes do intestino de Delia coarctata (Fallen, 1825) encontraram valores de maior atividade em $\mathrm{pH} 4,5$.

Sabe-se que o $\mathrm{pH}$ ótimo de atividade de serino proteases do tipo tripsina-like presentes no extrato solúvel e no insolúvel isoladas de A. gemmatalis é de 8,5. Como resposta adaptativa ao uso de inibidores, essa lagarta pode estar expressando proteases que atuem em outras faixas de $\mathrm{pH}$, que não o alcalino. Com base nesses resultados, os ensaios bioquímico-cinéticos posteriores foram realizados em pH 4,6, afim de caracterizar apenas a(s) isoforma(s) de cisteíno protease(s) atuante(s) em $\mathrm{pH}$ ácido.

Outra classe de proteases que são ativas em $\mathrm{pH}$ ácido é a aspartil protease. Segundo Terra \& Ferreira (1994), em pH entre 2,5 e 3,5 a aspartil protease apresenta uma boa
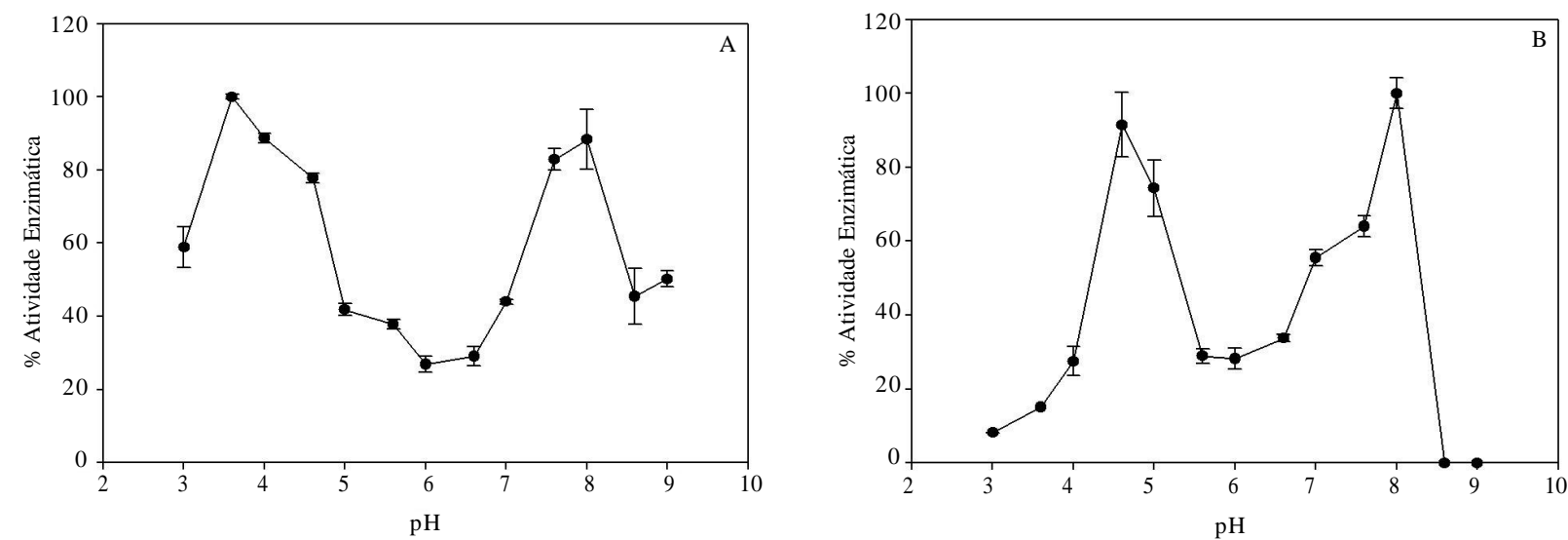

Figura 1 - Efeito do pH sobre a atividade de cisteíno proteases do extrato enzimático obtido do intestino médio de Anticarsia gemmatalis (Hübner, 1818). Efeito do pH sobre a atividade enzimática da Fração Solúvel (A) e da Fração Insolúvel (B). 
atividade hidrolítica. A Pepstatina A inibe aspartil proteases do tipo pepsina, quimosina, catepsina $\mathrm{D}$ e renina. Como as análises enzimáticas para determinar os parâmetros da isoforma de cisteíno protease foram realizadas em $\mathrm{pH}$ ácido, foi necessária a adição de um inibidor de aspartil proteases que fosse inócuo a atividade da cisteíno protease. Dessa forma, foi testado o efeito da Pepstatina A sob a atividade de cisteíno protease em $\mathrm{pH}$ 4,6. Verificou-se que a presença desse inibidor em todas as concentrações testadas não reduziu significativamente a atividade de cisteíno proteases presentes tanto na Fração Solúvel como na Fração Insolúvel (Figuras 2A e 2B).

Os resultados encontrados estão de acordo com Fahmy et al. (2004), os quais observaram a não influência de Pepstatina A na atividade de cisteíno protease de trigo, obtendo um valor de $116 \%$ de atividade quando adicionado $1 \mu \mathrm{g}$ desse inibidor. Avila-Levy et al. (2003), estudando cisteíno proteases do tripanosoma Crithidia deanei (Carvalho, 1973) o qual é um parasita monoxênico de insetos, verificaram que a Pepstatina inibiu fracamente a enzima purificada.

A melhor temperatura de atividade das isoformas de cisteíno proteases presentes nas Frações Solúvel e Insolúvel foi de $45^{\circ} \mathrm{C}$ e $50^{\circ} \mathrm{C}$, respectivamente (Figuras $3 \mathrm{~A}$ e $3 \mathrm{~B})$. Os perfis de atividade obtidos apresentaram mais de um pico de atividade em diferentes valores de temperatura avaliados, sugerindo novamente a existência de diferentes isoformas de enzimas presentes no extrato enzimático. A

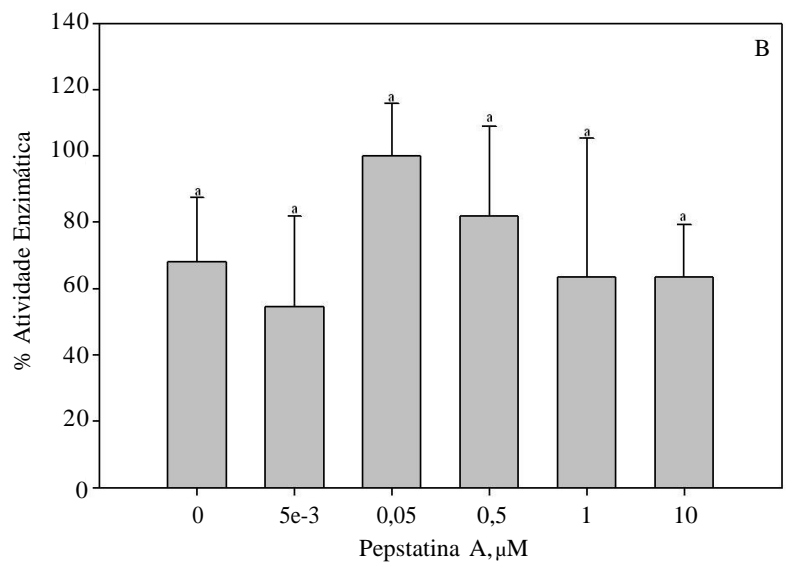

Figura 2 - Efeito de Pepstatina A na atividade de cisteíno proteases obtidas do intestino médio de Anticarsia gemmatalis (Hübner, 1818). Efeito da concentração de Pepstatina A sobre a atividade de cisteíno proteases da Fração Solúvel (A) e da Fração Insolúvel (B). Valores seguidos de mesma letra na coluna não diferem significativamente em nível de 5\% de probabilidade pelo teste de Tukey.
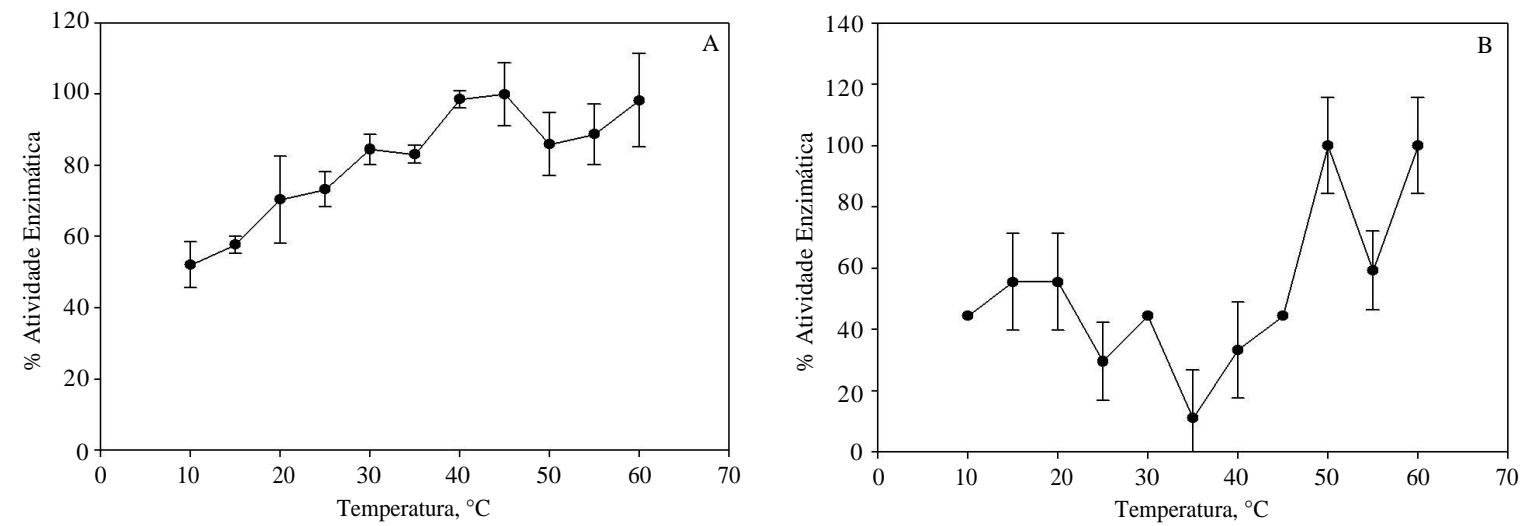

Figura 3 - Efeito da temperatura sobre a atividade de cisteíno proteases do extrato enzimático obtido do intestino médio de Anticarsia gemmatalis (Hübner, 1818). Efeito da temperatura sobre a atividade enzimática da Fração Solúvel (A) e Fração Insolúvel (B). 
faixa de temperatura ótima determinada no presente trabalho é semelhante à encontrada por Zhao et al. (1998), em estudos de cisteíno protease de Helicoverpa armigera (Hübner, 1805).

Para avaliar os parâmetros cinéticos da isoforma de cisteíno protease em $\mathrm{pH} 4,6$, foram utilizadas diferentes concentrações de substrato que variaram de 0,4 a 4,0 mM para a Fração Solúvel e de 0,05 a 1,0 mM para Fração Insolúvel. O perfil de atividade para a Fração Solúvel foi realizado a $45^{\circ} \mathrm{C}$ e o para a Fração Insolúvel a $50^{\circ} \mathrm{C}$. Observou-se que essas isoformas da Fração Solúvel (Figura 4A) e Fração Insolúvel (Figura 4B) apresentaram curvas hiperbólicas seguindo o modelo cinético de MichaelisMenten na faixa de concentrações de substrato analisadas.

Os valores de $\mathrm{K}_{\mathrm{M} \text { app }} \mathrm{e} \mathrm{V}_{\text {máx app, }}$ para as isoformas de cisteíno proteases das Frações Solúvel e Insolúvel de A. gemmatalis, estão apresentados na Tabela 1. De acordo com Segel (1979), a constante de Michaelis indica a "adequacidade" relativa de substratos para uma determinada enzima. Como se pode observar, o valor de $\mathrm{K}_{\mathrm{M} \text { app }}$ para a Fração Insolúvel é menor do que o valor obtido para a Fração Solúvel, o que sugere uma melhor adaptação do substrato L-BApNA ao centro ativo da isoforma presente na Fração Insolúvel. Outros autores encontraram valores de $\mathrm{K}_{\mathrm{M}}$ próximos aos obtidos neste estudo, como é o caso de Mohamed et al. (2005) que determinaram um $\mathrm{K}_{\mathrm{M}}$ de $0,6 \mathrm{mM}$ para cisteíno protease do parasita Fasciola gigantica sobre o substrato L-BApNA, Zhu et al. (2008) que obtiveram um $\mathrm{K}_{\mathrm{M}}$ de $0,069 \mathrm{mM}$ para

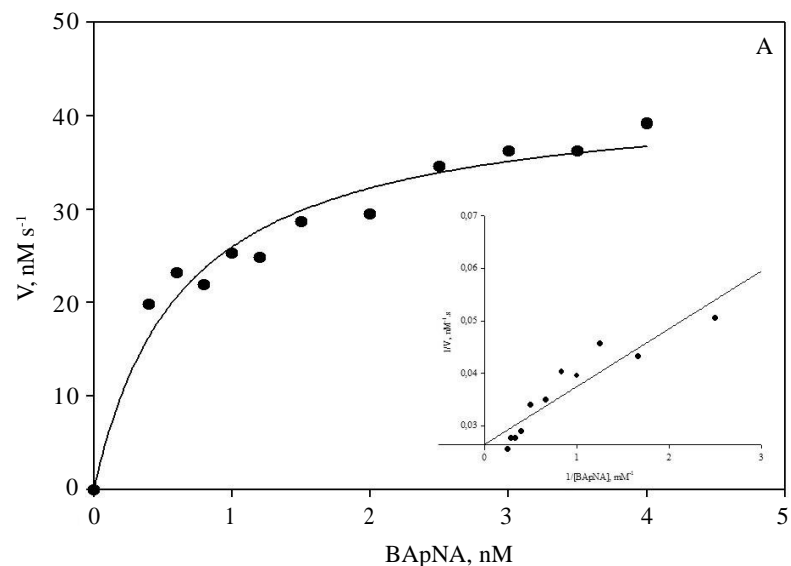

catepsina L-like do pepino do mar Stichopus japonicus (Selenka, 1867) e Cristofoletti et al. (2005), que avaliando algumas propriedades da catepsina L-like de Tenebrio molitor (Linnaeus, 1758), obteveram um $\mathrm{K}_{\mathrm{M}}$ de $0,05 \mathrm{mM}$, $0,14 \mathrm{mM}$ e $0,12 \mathrm{mM}$ sobre os substratos Z-FR-MCA, ZRR-MCA e Z-R-MCA, respectivamente.

Essa isoforma de cisteíno protease também foi caracterizada usando inibidores específicos. Um dos inibidores mais comumente utilizados para caracterização de cisteíno proteases é o E-64, por ser um inibidor irreversível, não competitivo de tiol proteases. A análise do efeito de concentração de E-64 na Fração Solúvel (Figura 5A) mostrou que cisteíno proteases presentes nessa fração são insensíveis a esse inibidor. Na literatura. temos que legumaína é uma endopeptidase caracterizada por não ser afetada por esse clássico inibidor, porém por outras cistatinas (Alavarez-Fernandez et al., 1999). A isoforma da Fração Solúvel caracterizada nesse trabalho possivelmente pertence a essa família de enzimas, porém testes com outras cistatinas deverão ser realizados para se confirmar que as cisteíno proteases da Fração Solúvel são cisteíno proteases legumaína-like. O efeito da concentração de E-64 na Fração Insolúvel (Figura 5B) mostrou que a atividade dessas cisteíno proteases decresce consideravelmente com $100 \mu \mathrm{M}$ de E-64 na mistura reacional, indicando uma inibição parcial dessas enzimas. Esse resultado é um indicativo da presença de cisteíno protease do tipo papaína-like no intestino de A. gemmatalis. Colebatch et al. (2001), trabalhando com

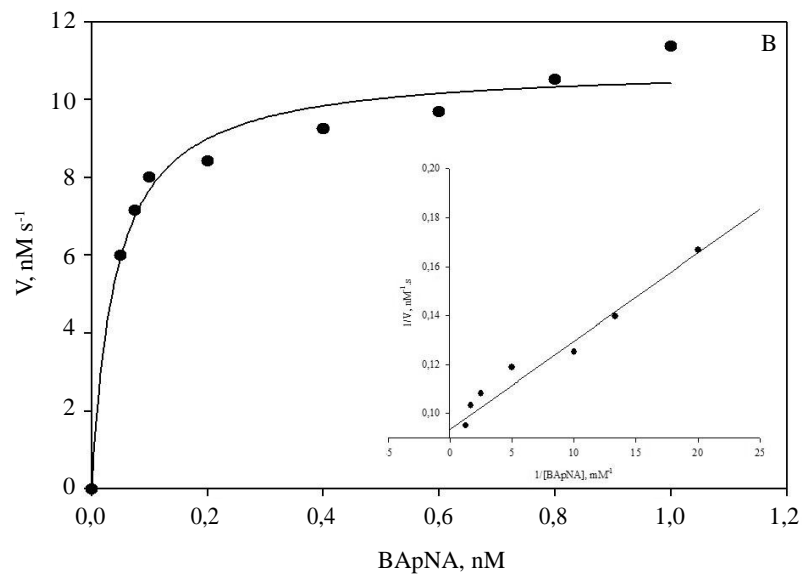

Figura 4 - Gráfico de Michaelis-Menten da atividade de cisteíno proteases do intestino médio de Anticarsia gemmatalis (Hübner, 1818). Inserção: Gráfico de Lineaweaver-Burk da atividade do extrato enzimático sobre L-BApNA. Os pontos são experimentais. A linha contínua traçada foi baseada em dados teóricos, utilizando-se a equação de MichaelisMenten para a obtenção dos valores de $\mathrm{K}_{\mathrm{M} \text { app }}$ e $\mathrm{V}_{\text {max app }}$. Gráfico de Michaelis-Menten da atividade enzimática da Fração Solúvel (A) e da Fração Insolúvel (B). 
proteases digestivas do percevejo Creontiades dilutus (Stal, 1859), também observaram a inibição parcial de cisteíno proteases presentes no intestino médio por E-64.

Tabela 1 - Parâmetros cinéticos de isoforma de cisteíno protease de A. gemmatalis.

\begin{tabular}{ccc}
\hline Fração & $\mathrm{K}_{\mathrm{M}}$ & $\mathrm{V}_{\text {máx }}$ \\
\hline Solúvel & $0,6398 \mathrm{mM}$ & $42,556 \mathrm{Nm} \mathrm{s}^{-1}$ \\
Insolúvel & $0,0413 \mathrm{mM}$ & $10,854 \mathrm{nM} \mathrm{s}^{-1}$ \\
\hline
\end{tabular}
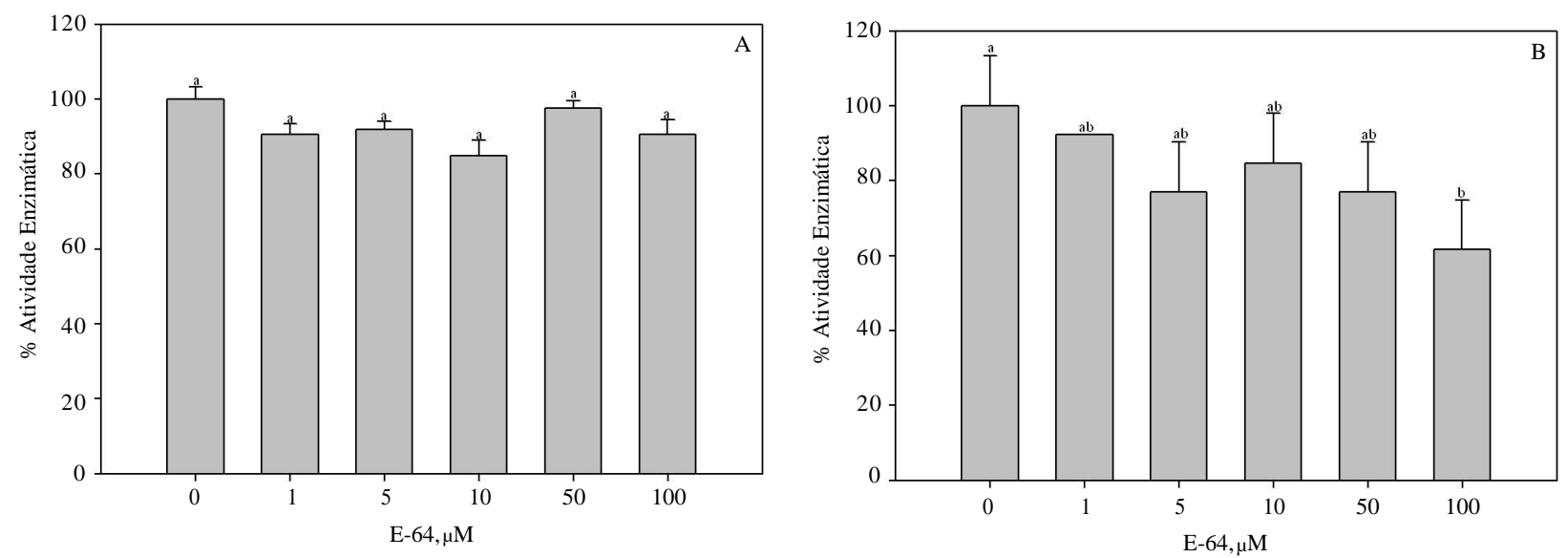

Figura 5 - Efeito de E-64 na atividade de cisteíno proteases do intestino médio de Anticarsia gemmatalis (Hübner, 1818). Efeito da concentração de E-64 sobre a atividade de cisteíno proteases da Fração Solúvel (A) e da Fração Insolúvel (B). Valores seguidos de mesma letra na coluna não diferem significativamente em nível de 5\% de probabilidade pelo teste de Tukey.
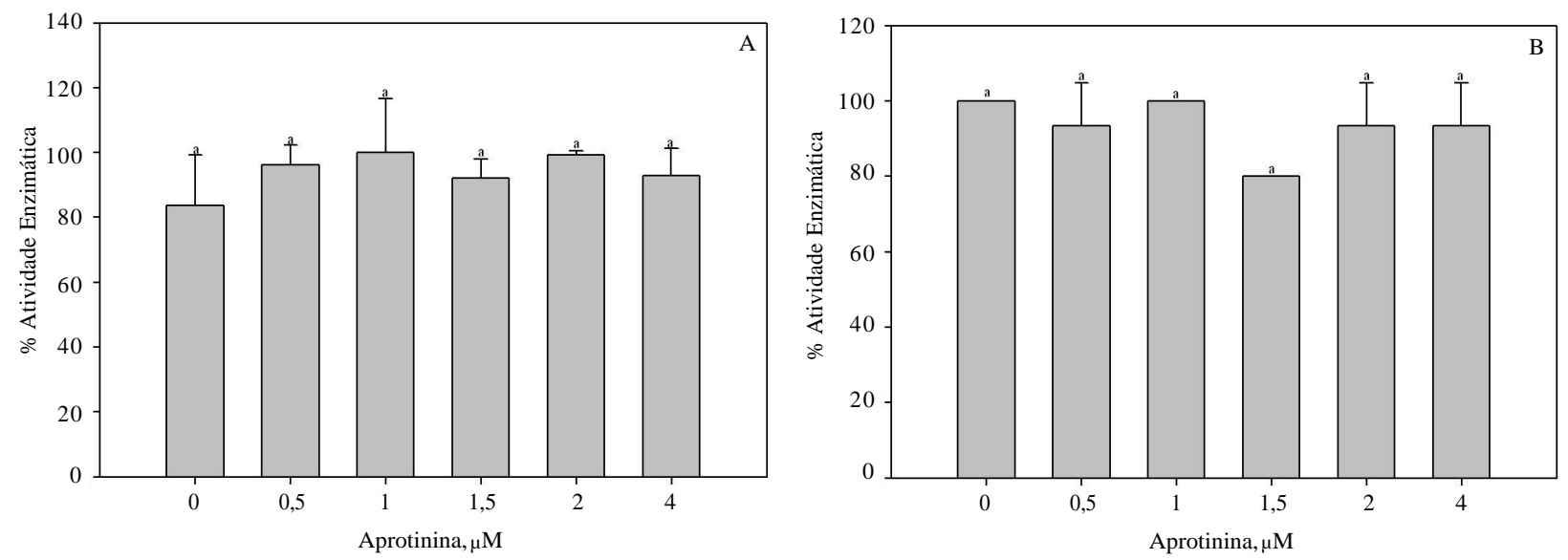

Figura 6 - Efeito de aprotinina na atividade de cisteíno proteases do intestino médio de Anticarsia gemmatalis (Hübner, 1818). Efeito da concentração de aprotinina sobre a atividade de cisteíno proteases da Fração Solúvel (A) e da Fração Insolúvel (B). Valores seguidos de mesma letra na coluna não diferem significativamente em nível de 5\% de probabilidade pelo teste de Tukey.

Ciênc. agrotec., Lavras, v. 35, n. 3, p. 446-454, maio/jun., 2011 
foi observado que esse inibidor não teve efeito significativo, inibindo fracamente a enzima.

O EDTA é um inibidor de metalo proteases e proteases ativadas por metais divalentes. $\mathrm{O}$ efeito da concentração de EDTA sobre atividade das Frações Solúvel e Insolúvel está representado na Figura 7. Na Fração Solúvel, a adição de EDTA na mistura de reação promoveu um aumento significativo da atividade enzimática, mostrando que íons metálicos não são importantes para aumentar a atividade da enzima solúvel. Fahmy et al. (2004) obtiveram resultados semelhantes. Seus estudos com cisteíno protease de trigo Triticum aestivum L. (cv. Giza 164) demonstraram que EDTA não teve efeito sobre essa enzima quando acrescido à mistura de reação. Zhu et al. (2008) também observaram que EDTA não afetou a atividade de catepsina L de Stichopus japonicus (Selenka, 1867). Na Fração Insolúvel, ocorreu uma redução de $80 \%$ nos valores de atividade com o aumento da concentração de EDTA (Figura 7B). Isso demonstra a necessidade de íons metálicos para a atividade das cisteíno proteases da Fração Insolúvel. Avila-Levy et al. (2003) em seus estudos com tripanosoma Crithidia deanei purificaram uma cisteíno protease cálcio dependente. O uso de EGTA aboliu completamente a atividade dessa protease e o de EDTA reduziu para $30 \%$ sua atividade.

A Fração Solúvel apresentou uma diminuição significativa da atividade $5 \mathrm{mM}$ de íons cálcio foram adicionados ao meio de reação. Porém, com o aumento crescente desses íons a atividade foi se restabelecendo até atingir valores iguais ao controle. Avila-Levy et al. (2003) obtiveram padrão semelhante em cisteíno protease do tripanosoma Crithidia deanei. Provavelmente altas concentrações de cálcio melhoram a conformação da enzima propiciando, dessa forma, um aumento da atividade. A adição de $30 \mathrm{mM}$ de íons cálcio na mistura reacional teve um efeito inibitório significativo na Fração Insolúvel (Figura 8B), o que demonstra a presença de cisteíno proteases cálcio independentes. Fahmy et al. (2004) e Mohamed et al. (2005) obtiveram um efeito inibitório de íons cálcio sobre atividade de cisteíno proteases. Mohamed et al. (2005) obtiveram uma diminuição de $83 \%$ da atividade de cisteíno protease de trigo usando $2 \mathrm{mM}$ de $\mathrm{CaCl}_{2}$ e Fahmy et al. (2004) uma diminuição de $21 \%$ da atividade de cisteíno protease do platelminto Fasciola gigantica.
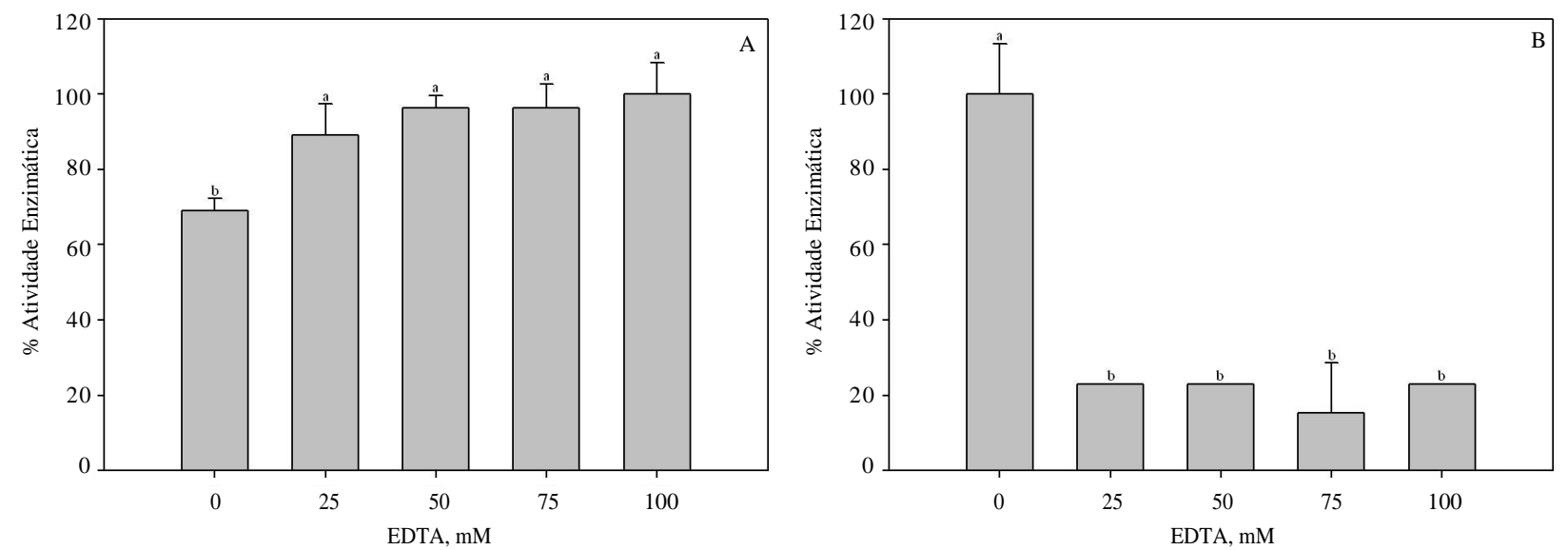

Figura 7 - Efeito de EDTA sobre a atividade de cisteíno proteases do extrato enzimático do intestino médio de Anticarsia gemmatalis (Hübner, 1818). Efeito da concentração de EDTA sobre a atividade da Fração Solúvel (A) e da Fração Insolúvel (B). Valores seguidos de mesma letra na coluna não diferem significativamente em nível de 5\% de probabilidade pelo teste de Tukey. 

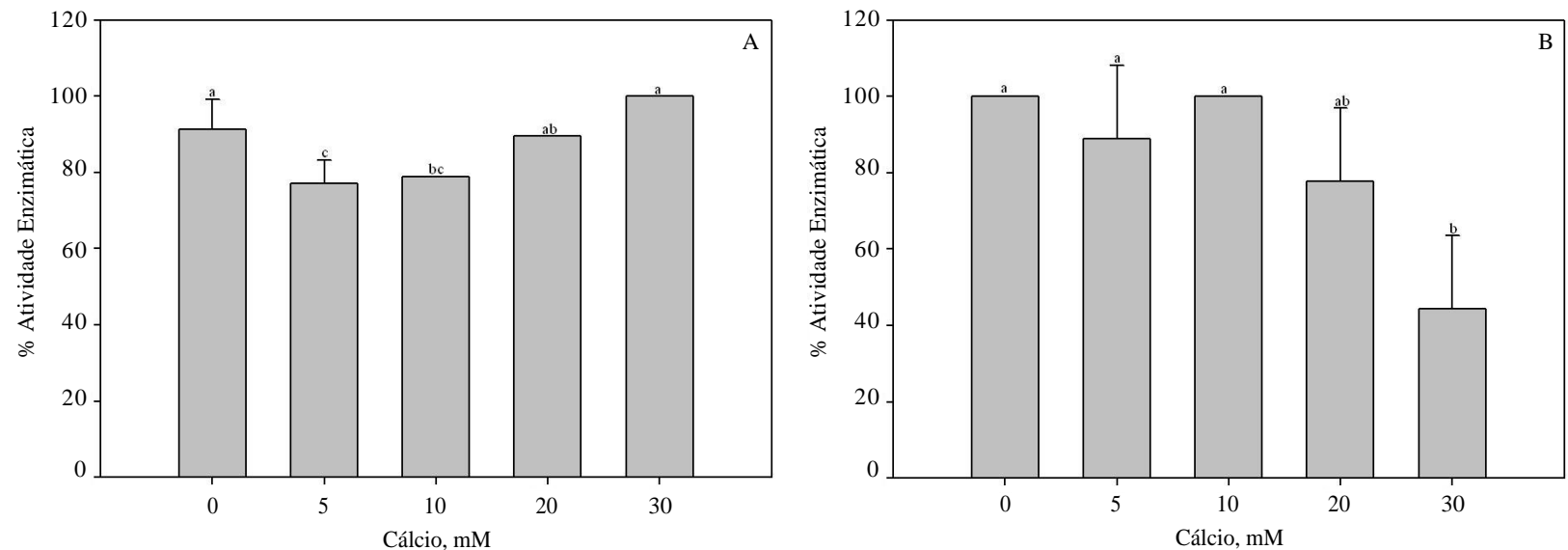

Figura 8 - Efeito de íons cálcio na atividade de cisteíno proteases do intestino médio de Anticarsia gemmatalis (Hübner, 1818). Efeito da concentração de íons cálcio sobre a atividade de cisteíno proteases da Fração Solúvel (A) e da Fração Insolúvel (B). Valores seguidos de mesma letra na coluna não diferem significativamente em nível de 5\% de probabilidade pelo teste de Tukey.

\section{CONCLUSÕES}

Como demonstrado pelo presente trabalho, foi encontrado cisteíno proteases no intestino médio de A. gemmatalis, apresentando atividades em diferentes $\mathrm{pH}$ 's devido, provavelmente, a existências de diferentes isoformas em seu intestino. Dessa forma, foram caracterizadas as isoformas acídicas de cisteíno proteases. Essas auxiliam no processo de digestão protéica do inseto e podem servir de alvos para o controle dessa praga agrícola.

\section{AGRADECIMENTOS}

À Fundação de Amparo à Pesquisa do Estado de Minas Gerais (FAPEMIG), à Coordenação de Aperfeiçoamento de Pessoal de Nível Superior (CAPES), ao Conselho Nacional de Desenvolvimento Científico e Tecnológico (CNPq) e ao Instituto Nacional de Ciência e Tecnologia em Interação Planta-Praga (INCT-IPP) pelo apoio financeiro e concessão de bolsas de estudo.

\section{REFERÊNCIAS BIBLIOGRÁFICAS}

ALAVAREZ-FERNANDEZ, M.; BARRETT, A.J.; GERHARTZ, B.; DANDO, P.M.; NI, J.; ABRAHAMSON, M. Inhibition of mammalian legumain by some cystatins is due to a novel second reactive site. Journal of Biological Chemistry, Bethesda, v.274, n.27, p.1919519203, July 1999.

COLEBATCH, G.; EAST, P.; COOPER, P. Preliminary characterisation of digestive proteases of the green mirid, Creontiades dilutus (Hemiptera: Miridae). Insect
Biochemistry and Molecular Biology, Amsterdam, v.31, n.4/5, p.415-423, Mar. 2001.

CRISTOFOLETTI, P.T.; RIBEIRO, A.F.; TERRA, W.R. The cathepsin L-like proteinases from the midgut of Tenebrio molitor larvae: sequence, properties, immunocytochemical localization and function. Insect Biochemistry and Molecular Biology, Amsterdam, v.35, n.8, p.883-901, Aug. 2005.

D'AVILA-LEVY, C.M.; SOUZA, R.F.; GOMES, R.C.; VERMELHO, A.B.; BRANQUINHA, M.H. A novel extracellular calcium-dependent cysteine proteinase from Crithidia deanei. Archives of Biochemistry and Biophysics, Nova York, v.420, n.1, p.1-8, Dec. 2003.

ERLANGER, B.F.; KOKOWSKY, N.; COHEN, W. The preparation and properties of two new chromogenic substrates of trypsin. Archives of Biochemistry and Biophysics, New York, v.95, n.2, p.271-278, Nov. 1961.

FAHMY, A.S.; ALI, A.A.; MOHAMED, S.A.

Characterization of a cysteine protease from wheat Triticum aestivum (cv. Giza 164). Bioresource Technology, New York, v.91, n.3, p.297-304, Feb. 2004.

HOFFMAN-CAMPO, C.B.; OLIVEIRA, E.B.; MOSCARDI, F. Criação massal de lagarta da soja (Anticarsia gemmatalis). Londrina: Embrapa-CNPSo, 1985. 23p. (Documentos, 10). 
MENEGHETTI, R.C.; BALARDIN, R.S.; CORTE, G.D.; FAVERA, D.D.; DEBONA, D. Avaliação da ativação de defesa em soja contra Phakopsora pachyrhizi em condições controladas. Ciência e Agrotecnologia, Lavras, v.34, n.4, p.823-829,jul./ago., 2010.

MOHAMED, S.A.; FAHMY, A.S.; MOHAMED, T.M.; HAMDY, S.M. Proteases in egg, miracidium and adult of Fasciola gigantica. characterization of serine and cysteine proteases from adult. Comparative Biochemistry and Physiology (B), Amsterdam, v.142, n.2, p.192-200, Oct. 2005.

OLIVEIRA, M.G.A.; SIMONE, S.G. de; XAVIER, L.P.; GUEDES, R.N.C. Partial purification and characterization of digestive trypsin-like proteases from the velvet bean caterpillar, Anticarsia gemmatalis. Comparative Biochemistry and Physiology (B), Amsterdam, v.140, n.3, p.369-380, Mar. 2005.

PEREIRA, M.E.; DÖRR, F.A.; PEIXOTO, N.C.; LIMAGARCIA, J.F.; DÖRR, F.; BRITO, G.G. Perspectives of digestive pest control with proteinase inhibitors that mainly affect the trypsin-like activity of Anticarsia gemmatalis Hübner (Lepidoptera: Noctuidae). Brazilian Journal of Medical and Biological Research, Ribeirão Preto, v.38, n.11, p.1633-1641, Nov. 2005.

PILON, A.M.; OLIVEIRA, M.G.A.; GUEDES, R.N.C. Protein digestibility, protease activity and postembryonic development of the velvetbean caterpillar Anticarsia gemmatalis exposed to the trypsin-inhibitor benzamidine. Pesticide Biochemistry and Physiology, Amsterdam, v.86, n.1, p.23-29, Sept. 2006.

PYATI, P.S.; BELL, H.A.; FITCHES, E.; PRICE, D.R.G.; GATEHOUSE, A.M.R.; GATEHOUSE, J.A. Cathepsin Llike cysteine proteinase (DcCathL) from Delia coarctata (wheat bulb fly): basis of insecticidal activity. Insect Biochemistry and Molecular Biology, Amsterdam, v.39, n.8, p.535-546, Aug. 2009.

ROSSI, G.D.; SANTOS, C.D. dos; CARVALHO, G.A.; CORREAA, A.D.; ABREU, C.M.P.de; CARVALHO, G.A. Enzimas digestivas do bicho-mineiro do cafeeiro
Leucoptera coffeella (Guérin-Mèneville \& Perrottet, 1842) (Lepidoptera: Lyonetiidae). Ciência e Agrotecnologia, Lavras, v.33, n. Ed. Especial, p.18711876, 2009.

SEGEL, I.H. Bioquímica: teoria e problemas. Rio de Janeiro: LTC, 1979. 527p.

TERRA, W.R.; FERREIRA, C. Insect digestive enzymes: properties, compartmentalization and function.

Comparative Biochemistry and Physiology (B), Amsterdam, v.109, n.1, p.1-62, Sept. 1994.

TIFFIN, P.; GAUT, B.S. Molecular evolution of the wound-induced serine protease inhibitor wip 1 in zea and related genera. Molecular Biology and Evolution, Oxford, v.18, n.11, p.2092-2101, Nov. 2001.

VISÔTTO, L.E.; OLIVEIRA, M.G.A.; RIBON, A.O.B.; MARES-GUIA, T.R.; GUEDES, R.N.C. Characterization and identification of proteolytic bacteria from the gut of the velvetbean caterpillar (Lepidoptera: Noctuidae). Environmental Entomology, Lanham, v.38, n.4, p.10781085, Aug. 2009.

XAVIER, L.P.; OLIVEIRA, M.G.A.; GUEDES, R.N.C.; SANTOS, A.V.; SIMONE, S.G. de. Trypsin-like activity of membrane-bound midgut proteases from Anticarsia gemmatalis (Lepidoptera: Noctuidae). European Journal of Entomology, Ceske Budejovice, v.102, n.2, p.147-153, Jan. 2005.

ZHAO, X.F.; WANG, J.X.; WANG, Y.C. Purification and characterization of a cysteine proteinase from eggs of the cotton boll worm, Helicoverpa armigera. Insect Biochemistry and Molecular Biology, Amsterdam, v.28, n.4, p.259-264, Apr. 1998.

ZHU, B.; ZHAO, L.; SUN, L.; LI, D.; MURATA, Y.; YU, L.; ZHANG, L. Purification and characterization of a Cathepsin L-Like enzyme from the body wall of the sea cucumber Stichopus japonicus. Bioscience, biotechnology, and biochemistry, Tokyo, v.72, p.14301437, June 2008. 